\title{
Meta-analysis and systematic review of influence of different humidified carbon dioxide on intraoperative and postoperative gynaecological laparoscopic surgery
}

\author{
Ping Xu, Yufei Li, Jing Ren \\ Operating Room, the Fourth Hospital of Shijiazhuang, Shijiazhuang, China \\ Contributions: (I) Conception and design: P Xu, J Ren; (II) Administrative support: Y Li; (III) Provision of study materials or patients: P Xu, J Ren; \\ (IV) Collection and assembly of data: All authors; (V) Data analysis and interpretation: P Xu, Y Li; (VI) Manuscript writing: All authors; (VII) Final \\ approval of manuscript: All authors. \\ Correspondence to: Jing Ren. Operating Room of Hebei Reproductive Obstetrics Hospital, 27 Shifeng Road, Qiaoxi District, Shijiazhuang, China. \\ Email: yangguangmingm@163.com.
}

Background Due to the characteristics of non-flammable carbon dioxide and high blood solubility, the
use of carbon dioxide to establish artificial pneumoperitoneum in clinical laparoscopic surgery at present
has stable pressure and mild complications after absorption, which is easy to be accepted by the majority of
patients.

Methods: The key terms "gynaecological laparoscopic surgery", "carbon dioxide", "gas belly" and "humidity" were used, and relevant documents were searched using several databases. Relevant factors were analyzed, such as intraoperative conditions, length of operation, postoperative pain, use of analgesics (morphine), and core temperature.

Results: Searching of the databases from establishment to February 28, 2021 revealed 119 related publications, of which 13 were included in the meta-analysis. The results showed that $90 \%$ humidified carbon dioxide could effectively prevent patients from hypothermia relative to dry gas during surgery at standard room temperature and could also relieve pain on the day after surgery. The use of postoperative analgesics was reduced, and there were significant differences in indicators such as hospitalization time. Compared with dry carbon dioxide, there was still a significant difference in pain on the day after surgery using humidified carbon dioxide perfusion $[M D=1.59(1.35,1.82), \mathrm{Z}=13.04(\mathrm{P}<0.00001)$, $\mathrm{df}=5$ on the first day after surgery]. The dosage of analgesic drugs (morphine) one day after laparoscopic surgery was significantly improved $[\mathrm{MD}=0.25(-0.04,0.54), \mathrm{Z}=1.68(\mathrm{P}=0.09), \mathrm{df}=3$ on the day after surgery].

Discussion: Humidifying carbon dioxide by $90 \%$ can effectively prevent hypothermia during surgery, relieve pain on the day after surgery, and improve laparoscopic fogging during surgery.

Keywords: Gynaecological laparoscopy; humidity; carbon dioxide; pain; hypothermia

Submitted May 15, 2021. Accepted for publication Jul 02, 2021.

doi: 10.21037/apm-21-1517

View this article at: https://dx.doi.org/10.21037/apm-21-1517

\section{Introduction}

Laparoscopy is widely used in clinical obstetrics and gynaecology surgery, and compared with traditional methods, it is less invasive, safer, and produces satisfactory results. The establishment of a carbon dioxide pneumoperitoneum with proper pressure, humidity (0-5\% relative humidity), and temperature $\left(20-25^{\circ} \mathrm{C}\right)$ is the basis for the implementation of gynaecological laparoscopic surgery.

However, studies have shown complications such as hypercapnia and acidosis may occur when humidified carbon dioxide is used. Temperature changes may also 
occur including intraoperative hypothermia (perioperative hypothermia) which may be caused by dry carbon dioxide gas stimulating mucosa, damaging tissues, and increasing oxygen consumption to disrupt the thermal balance of the body. In turn, this may prolong postoperative hospital stays, increase abdominal adhesions, and cause other health problems.

The technique of establishing a pneumoperitoneum by the intraoperative infusion of humidified carbon dioxide has been studied and applied clinically to reduce these effects (1).

Several kinds of humidification devices to establish carbon dioxide humidification of the pneumoperitoneum have been proposed. The first use of humidifying gas was in 1991 by Koninckx et al. (2), who used a "Persufflator" device to moisten the pneumoperitoneal environment. Their theory was that this would reduce the length of the operation and the risk of complications, better expose the laparoscopic field of vision, and prevent the formation of smoke during the operation leading to fogging of the laparoscopic endoscope.

Korell et al. and Ott et al. found that the use of gas humidification using $88-95 \%$ perfusion to form a carbon dioxide pneumoperitoneum could reduce the probability of perioperative hypothermia and intraperitoneal mucosal injury, decrease postoperative pain, and shorten recovery time in laparoscopic obstetrics surgery $(3,4)$. However, many practitioners and researchers doubt the positive benefits observed can be fully attributed to the use of humidified carbon dioxide gas perfusion.

The innovation of this study lies in the integrated analysis of relevant literature on the influence of pneumoperitoneum established by different carbon dioxide gas humidity on gynecological laparoscopic surgery. The following factors that may influence the operation during and after operation were mainly evaluated: volume of intraoperative gas consumption, duration of surgery, fog of laparoscopic endoscopic lens, length of postoperative hospital stay (recovery time), use of analgesics (morphine), and postoperative pain on the day after surgery.

We present the following article in accordance with the PRISMA reporting checklist (available at https://dx.doi. org/10.21037/apm-21-1517).

\section{Methods}

\section{Literature search}

Composite logic retrieval and Boolean logic retrieval were used to select relevant literature, and the search terms "gynaecological laparoscopic surgery", "carbon dioxide", "gas belly" and "humidity" were used. The PubMed, Medline, Embase, Chinese Biomedical Literature, China National Knowledge Network (CNKI), Wanfang, VIP, and Google Academic databases were searched. All literature and reference lists of published reviews were traced to find those not indexed by the database, and the search time was from the establishment of the database to February 28, 2021. The quality of literature was evaluated using Rev Man 5.3 provided by the Cochrane system, and all search words were combined freely.

\section{Inclusion and exclusion criteria}

The included literature met all the following criteria: (I) the subjects of the study were recipients of gynaecological abdominal surgery; (II) the study methods were random studies; and (III) the research data included postoperative pain, postoperative analgesics use, length of stay, iatrogenic hypothermia, and recovery time, as well as intraoperative lens fogging, operation time, and intraoperative gas consumption volume.

Literature was excluded for any of the following reasons: (I) laparoscopy was combined with other medical methods; (II) other unrelated factors were found during the operation to prolong the operation time; (III) the literature data was duplicated; (IV) accurate data could not be obtained; and (V) reliable data could not be provided.

\section{Quality assessment}

The Newcastle-Ottawa Scale (NOS) of the Cochrane Collaboration was utilized to evaluate the pathologic control studies. A star system (full score is nine stars) was adopted to measure the results of study subjects, case comparison, and inter-group comparison. Selected literature with seven stars or above was considered as high quality and having low risk bias, and that with one star or no stars was considered low quality and having high risk bias. Literature with twosix stars was considered to be of medium quality and having medium risk bias.

\section{Data extraction}

Data extracted included (I) first author and year of publication; (II) number of subjects; (III) number of cases of pneumoperitoneum established in gynaecological laparoscopy; (IV) year of study establishment; (V) research 


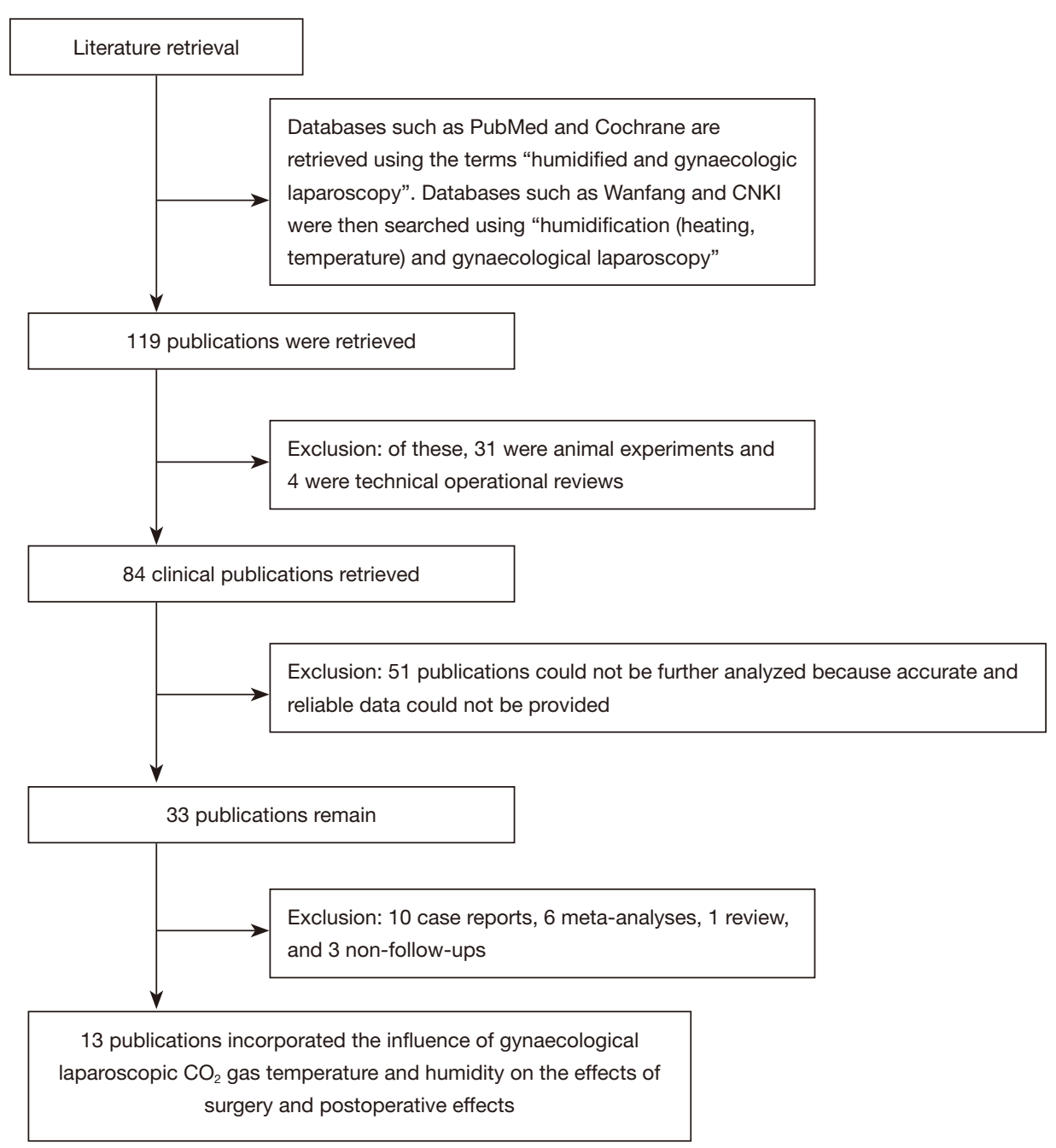

Figure 1 Schematic diagram of the literature screening process.

design type; and (VI) surgical instructions signs and types of surgery.

Evaluation indicators included: (I) postoperative analgesia; (II) use of analgesic drugs; (III) hypothermia; (IV) operation time; (V) recovery time; (VI) length of hospital stay; (VII) intraoperative lens fogging; and (VIII) intraoperative carbon dioxide gas consumption volume.

\section{Statistical methods}

Review manager 5.3 was adopted for meta-analysis. For continuous variables, MD or SMD and $95 \%$ confidence interval (CI) were used as the efficacy analysis statistics. The included literature was first tested for heterogeneity using a Q test, and Rev Man's risk of bias assessment chart was utilized to assess the risk bias. Each effect was expressed using a $95 \%$ CI. When the heterogeneity test showed that $\mathrm{P}>0.1$ and $\mathrm{I}^{2}<50 \%$, the fixed effects model was adopted and when the heterogeneity test showed that $\mathrm{P}<0.1$ and $\mathrm{I}^{2}>50 \%$, the random effects model was adopted.

\section{Results}

\section{Literature collection results and NOS scale rating}

A total of 119 publications were retrieved from the establishment of the database to February 2021 with 13 (5-17) meeting all criteria for further analysis as shown in Figure 1. NOS rating was then performed, and the general characteristics of the literature are shown in Table 1. 
Table 1 General information of the included literature

\begin{tabular}{|c|c|c|c|c|c|c|}
\hline Author & Operation time/min & Total & Humidified gas & Dry gas & Age of patient & Star rating system score \\
\hline Mao QY 2015 & 180 & 74 & 35 & 39 & - & 6 \\
\hline Sammour T 2010 & 108 & 20 & 10 & 10 & 44 & 5 \\
\hline Benavides R 2009 & 76 & 73 & 38 & 35 & 51.5 & 7 \\
\hline Davis SS 2006 & 83 & 22 & 11 & 11 & 42.55 & 6 \\
\hline Champion JK 2006 & 61 & 50 & 25 & 25 & 42.75 & 7 \\
\hline Diamond MP 2005 & 70 & 60 & 30 & 30 & - & 5 \\
\hline Yu TC 2013 & 96 & 190 & 95 & 95 & 46.5 & 5 \\
\hline Nguyen NT 2002 & 89 & 60 & 30 & 30 & 37 & 7 \\
\hline Demco L 2001 & 72 & 40 & 20 & 20 & 44 & 7 \\
\hline
\end{tabular}

\section{Evaluation results of literature risk bias}

Figure 2 is the funnel chart of the included research literature, and Figures 3 and 4 are the Rev Man analysis showing that the included literature are not biased. According to the funnel plot, the included literatures were distributed on both sides of the midline, which was basically symmetric, indicating that the included literatures had high research accuracy and no bias in publication. For each methodological feature of the included literature, the evaluation results were input into the software to generate a bias risk evaluation chart. From the chart, the random sequence generation (selection bias), allocation hiding (selection bias), blind method of result evaluation (measurement bias), and incomplete result data (followup bias, selective reporting (reporting bias) are obviously at low-risk bias. The blinding (implementation bias) and other low-risk bias evaluations of subjects and researchers are also not high. In cases where a certain bias evaluation of individual literature was relatively high, this was not considered to affect the research of analytical factors.

\section{Postoperative pain and analgesic use}

Figure 5 shows the use of humidified carbon dioxide to establish a pneumoperitoneum during laparoscopic surgery in obstetrics and gynaecology can greatly improve pain scores on the day after surgery $[M D=0.56(0.46,0.65)$,
$\mathrm{Z}=11.13(\mathrm{P}<0.00001), \mathrm{df}=3]$. In contrast to dry carbon dioxide gas to establish a pneumoperitoneum, there is a considerable difference in pain on the day after surgery $[\mathrm{MD}=1.59(1.35,1.82), \mathrm{Z}=13.04(\mathrm{P}<0.00001), \mathrm{df}=5$ on the first day after surgery]. Similarly, the forest plot in Figure 6 shows the use of humidified carbon dioxide perfusion remarkably improves the dosage of analgesic drugs (morphine) on the day of surgery and the day after, $[\mathrm{MD}$ $=0.25(-0.04,0.54), \mathrm{Z}=1.68(\mathrm{P}=0.09), \mathrm{df}=3$ on the surgery day; $M D=1.49(1.15,1.84), Z=8.58(P<0.00001), d f=3$ on the day after surgery]. Figure 7 shows the temperature forest plots of gynaecological laparoscopic heating and humidifying gas compared with standard room temperature dry gas during and after operation, and Figure 8 shows the temperature forest plots of the anesthesia recovery time and hospitalization days of heating humidified gas for gynaecological laparoscopy compared with standard room temperature dry gas.

\section{Surgical procedure}

The forest plots in Figure 9 show that compared with the use of dry carbon dioxide gas to establish a pneumoperitoneum, the consumption of carbon dioxide gas volume and the fogging of the laparoscopic endoscopic lens are substantially different, and the length of laparoscopic surgery is also significantly better using humidified 
gas [operating time $\mathrm{MD}=-0.38(-0.75,-0.02), \mathrm{Z}=2.04$ $(\mathrm{P}<0.00001), \mathrm{df}=4$; fogging of the endoscope lens $\mathrm{MD}=0.57$ (0.39, 0.74), $\mathrm{Z}=6.37(\mathrm{P}<0.00001), \mathrm{df}=3$; gas consumption volume $\mathrm{MD}=-0.82(-0.93,-0.70), \mathrm{Z}=14.36(\mathrm{P}<0.00001)$, $\mathrm{df}=7]$.

\section{Discussion}

During short-term surgery, hypothermia can improve the body's tolerance to ischemia and hypoxia and reduce the oxygen consumption of tissues and organs. However, prolonged operation time and low body temperature may cause complications, increase pain, and lengthen recovery times, and the use of humidified carbon dioxide gas to establish a pneumoperitoneum during laparoscopic gynaecological surgery can effectively avoid decreases in body temperature during prolonged operation times.

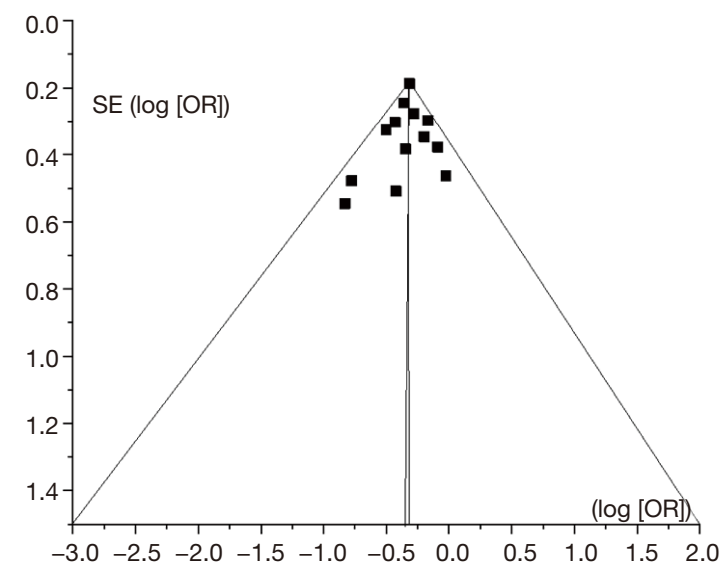

Figure 2 Funnel chart of included literature.
Carbon dioxide is the gas most used as it has several advantages over other gases including it being colorless and odorless, inexpensive, having low flammability, and being easily soluble in water.

As the volume of carbon dioxide gas consumed during the operation increases, continuous and frequent replenishment is required, and in this process, heat loss caused by gas exchange will further cause the body temperature to drop. This study showed that the use of humidified carbon dioxide gas to establish a pneumoperitoneum effectively reduced pain on the day after surgery and increased the core temperature during laparoscopic surgery.

In the study of Demco et al. (17), the use of humidified carbon dioxide gas to establish a pneumoperitoneum was shown to reduce the pain evaluation of patients after laparoscopic surgery and reduced the dosage of analgesic drugs (morphine), although these results were not supported by Birch et al. who in a similar study found no reduction in pain levels (18). The establishment of a pneumoperitoneum usually involves perfusion with gas at room temperature, that is, $20-21^{\circ} \mathrm{C}$, which can cause the body temperature to drop if the operation time is prolonged.

While Sajid et al. (19) found that the use of humidified gas to establish a pneumoperitoneum could effectively prevent body temperature from falling during laparoscopic surgery, there are many factors influencing this. Heat loss is usually caused by radiation, convection, conduction, and heat evaporation through the surface of the body and the respiratory tract. Evaporation of heat around the surgical wound during surgery, unheated inhaled anesthetic gas, peritoneal irrigation, intravenous infusion, and long operation times may also cause the patient's core body temperature to drop.

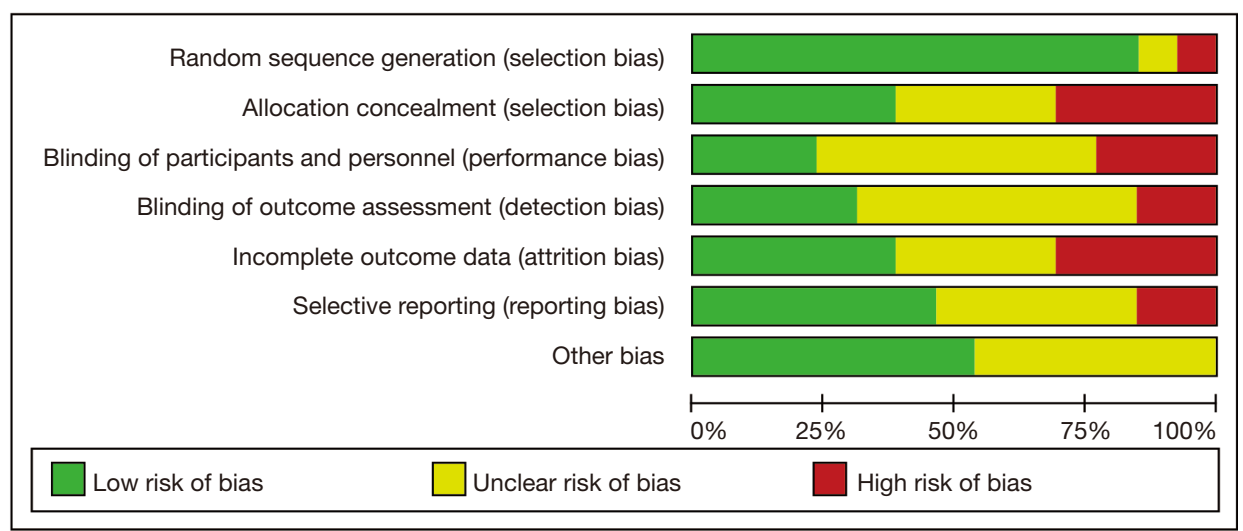

Figure 3 Risk bias evaluation results. 


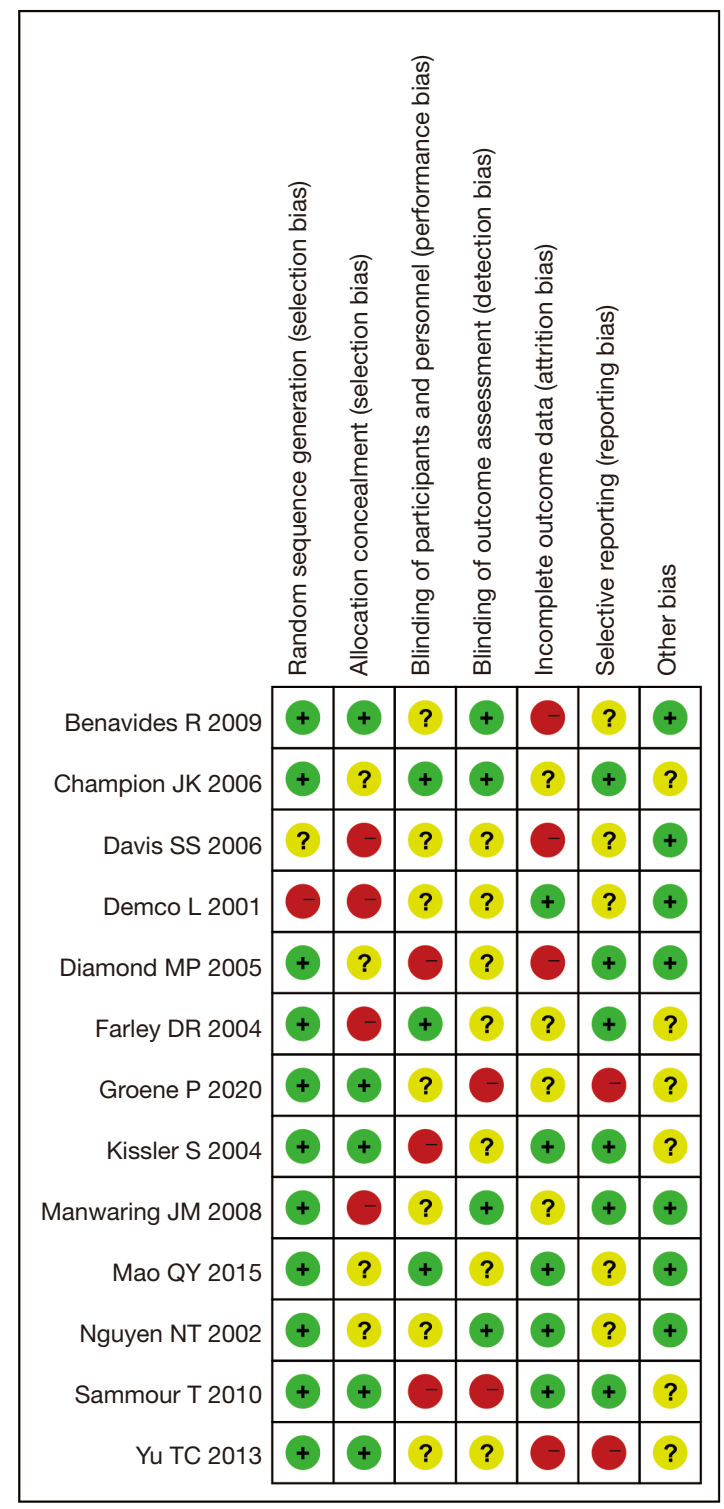

Figure 4 Deviation project risk in each study.

Studies have revealed that when the time of laparoscopic surgery was prolonged, especially when exceeding three hours, the probability of hypothermia and the volume of gas consumed during surgery significantly increase. After laparoscopic surgery, patients are prone to procedural complications such as hypokalemia, coagulopathy, and increased oxygen consumption, and an effective means to reduce the occurrence of complications during and after surgery is to prevent the fall in temperature. In addition, the degree of wound bleeding and postoperative wound infection are also related to hypothermia during surgery, which can also effectively shorten the postoperative recovery time of patients (20). In the analysis of body temperature items, this study focused on the significant heterogeneity of the research. The international use of external warming blankets during surgery is common and may have caused data errors when determining factors effecting body temperature.

There are significant differences in the length of hospital stay in patients who undergo laparoscopic surgery in obstetrics and gynaecology with the use of humidified carbon dioxide gas and dry carbon dioxide gas to establish a pneumoperitoneum, with the duration of hospital stay reduced in the former. However, it should be noted that in the literature included in this study, the length of hospitalization was short, which may affect the final analysis results.

The surgical field of vision during laparoscopy is extremely important, and serious consequences may evolve if it is blurred or impeded. The humidity created by a carbon dioxide pneumoperitoneum is one of the main factors for fogging of the laparoscopic endoscopic lens, and some researchers believe increasing humidified carbon dioxide will minimize the fogging effect. However, this proposal is not supported by the literature included in this study, which suggests there is no correlation between humidity and fogging, and that the carbon dioxide temperature is more likely to affect lens fogging (21).

Some researchers believe that carbonic acid generated by the use of dry carbon dioxide gas in establishing a pneumoperitoneum stimulates the diaphragm, causing diaphragm pain, radiating shoulder radiating pain, and other symptoms because of the low body temperature and slow carbon dioxide metabolism. In contrast, humidified carbon dioxide inhibits the production of inflammatory cytokines and reduces pain sensitivity.

However, it should be noted that there are no clinical studies to date proving peritoneal tissue is affected by a carbon dioxide pneumoperitoneum during laparoscopic surgery in obstetrics and gynaecology and animal experiments demonstrating that this reduces dryness of the peritoneum (22) are required. Long-term studies of postoperative effects and complications are also required.

\section{Conclusions}

Composite logic retrieval and Boolean logic retrieval were used to select 13 publications for meta-analysis to explore the influence of different degrees of humidified 
A

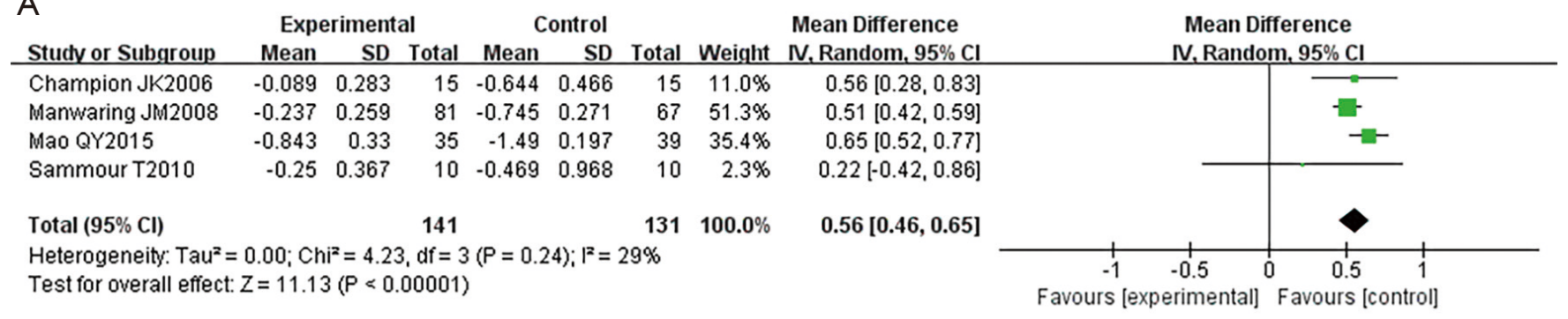

B

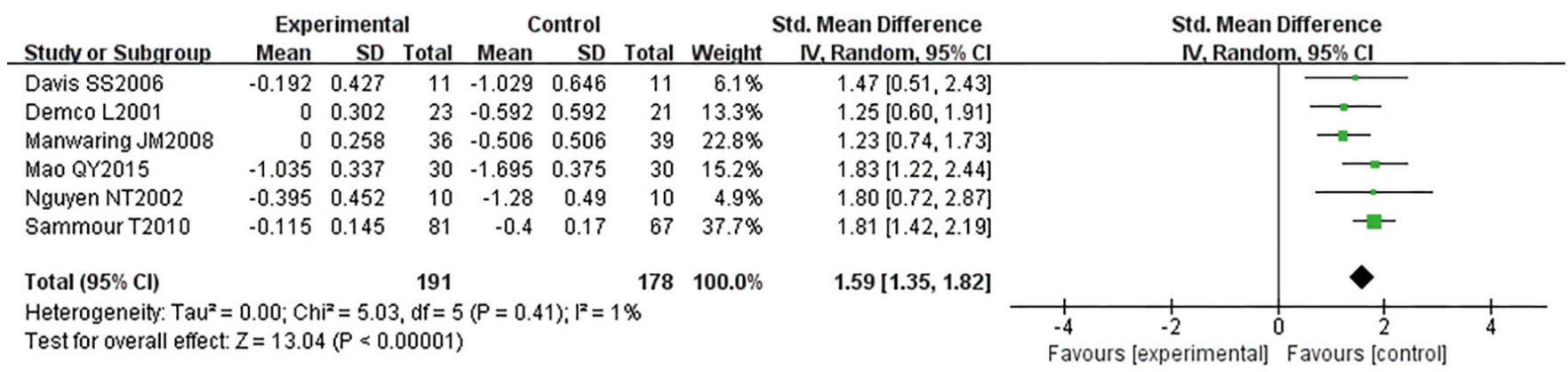

Figure 5 Forest plots of abdominal pain after gynaecological laparoscopic humidified gas compared with standard room temperature dry gas (A, the operation day; B, 1 day after the operation).

A

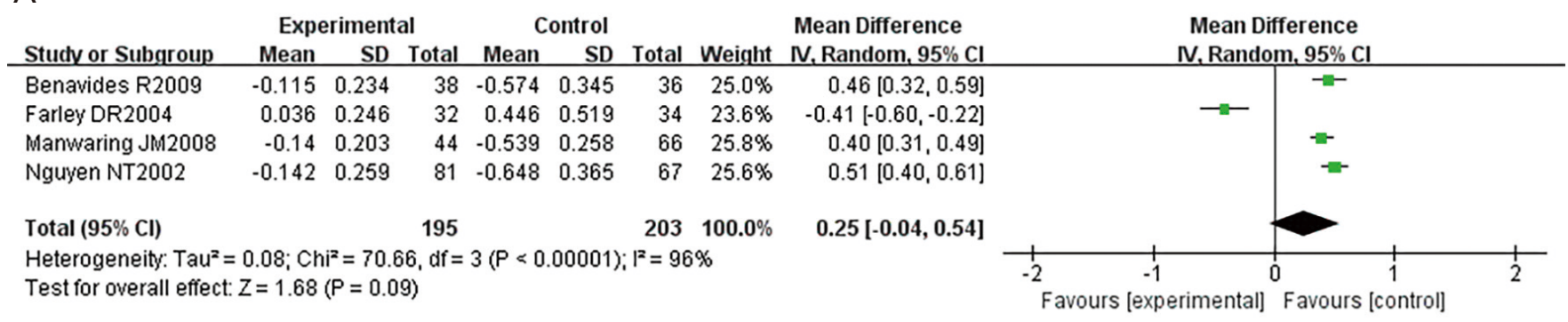

B

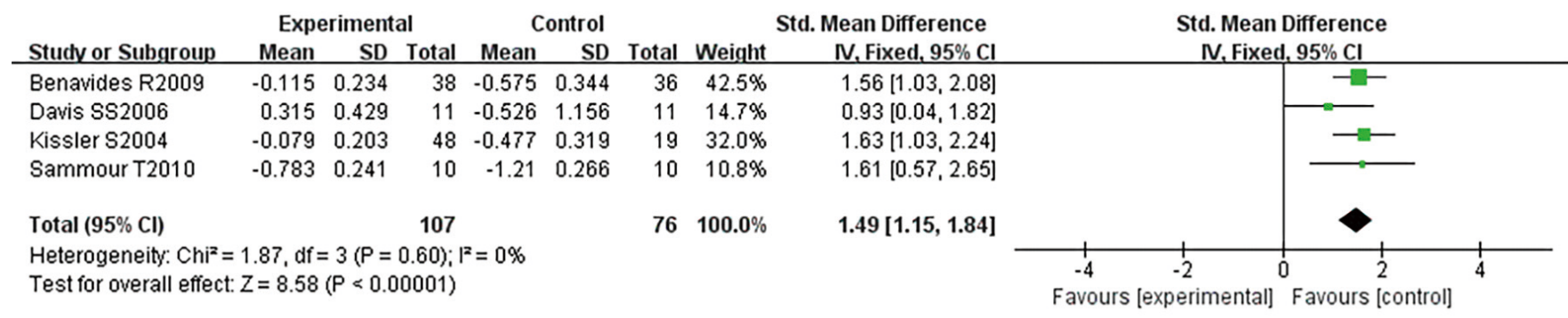

Figure 6 Forest plots of morphine usage after heating and humidifying gas in gynaecological laparoscopy compared with standard room temperature dry gas (A, the operation day; B, 1 day after the operation). 
A

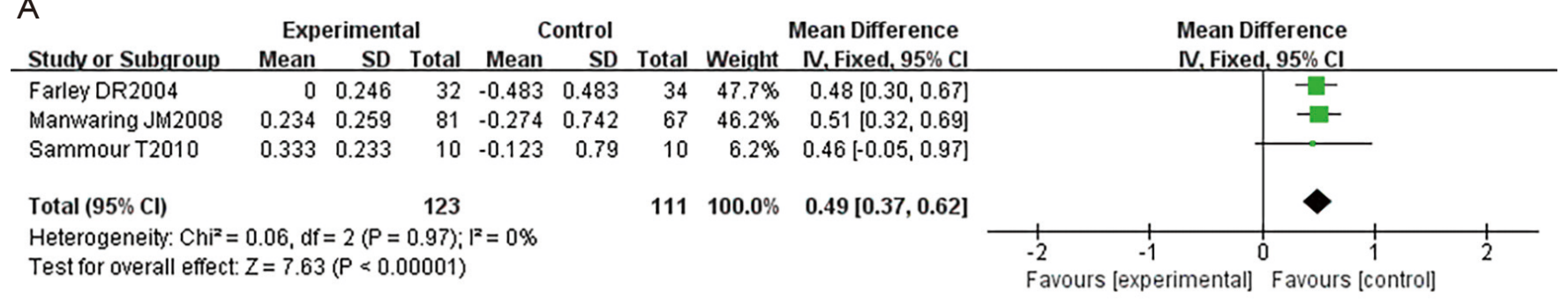

B

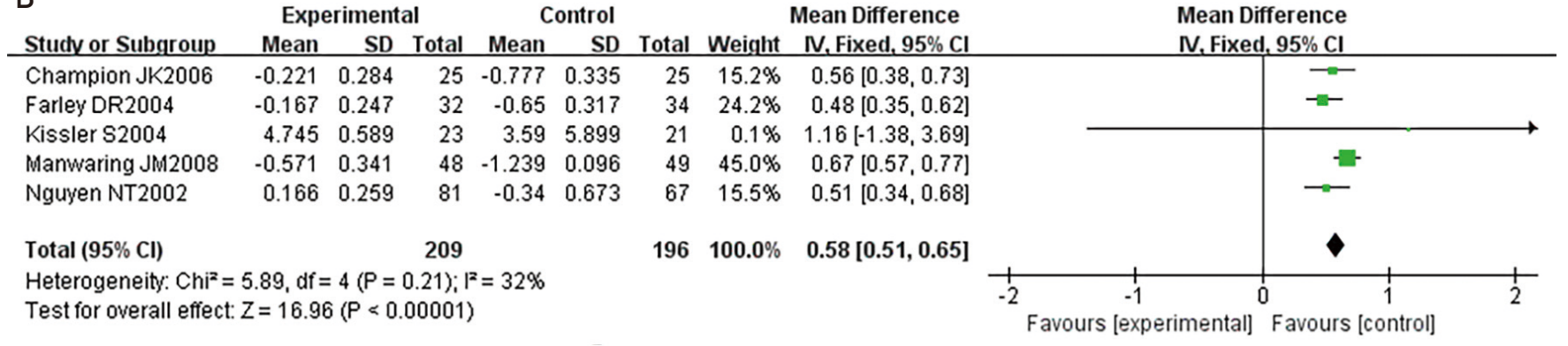

Figure 7 Temperature forest plots of gynaecological laparoscopic heating and humidifying gas compared with standard room temperature dry gas during and after operation (A, during the operation; B, after the operation).

A

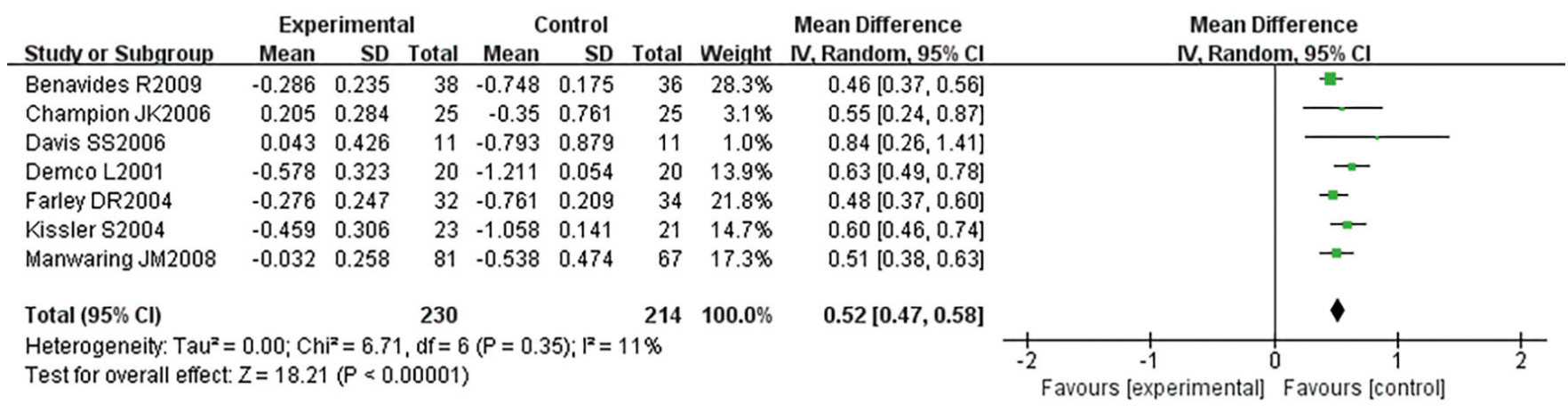

B

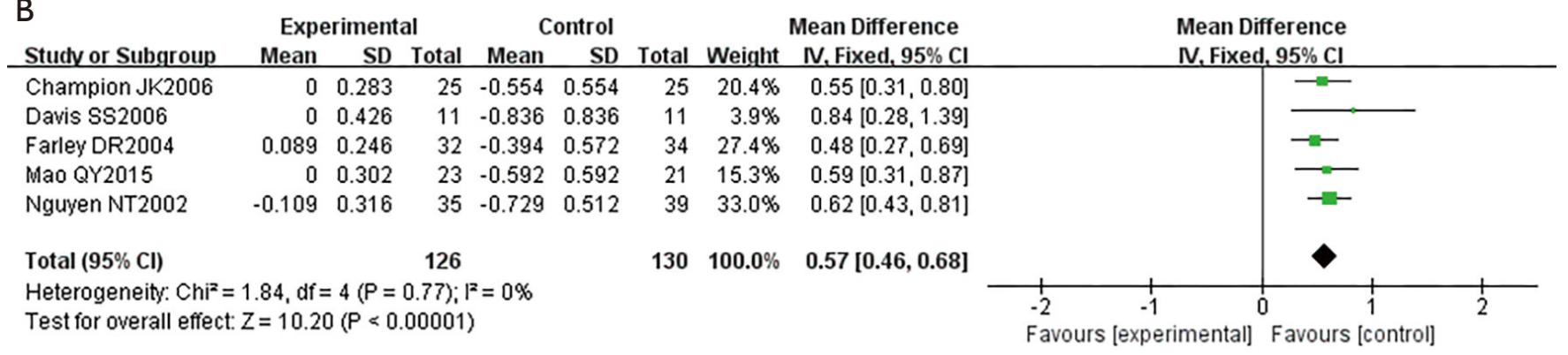

Figure 8 Temperature forest plots of the anesthesia recovery time and hospitalization days of heating humidified gas for gynaecological laparoscopy compared with standard room temperature dry gas (A, recovery time from anesthesia; B, hospitalization days after operation). 
A

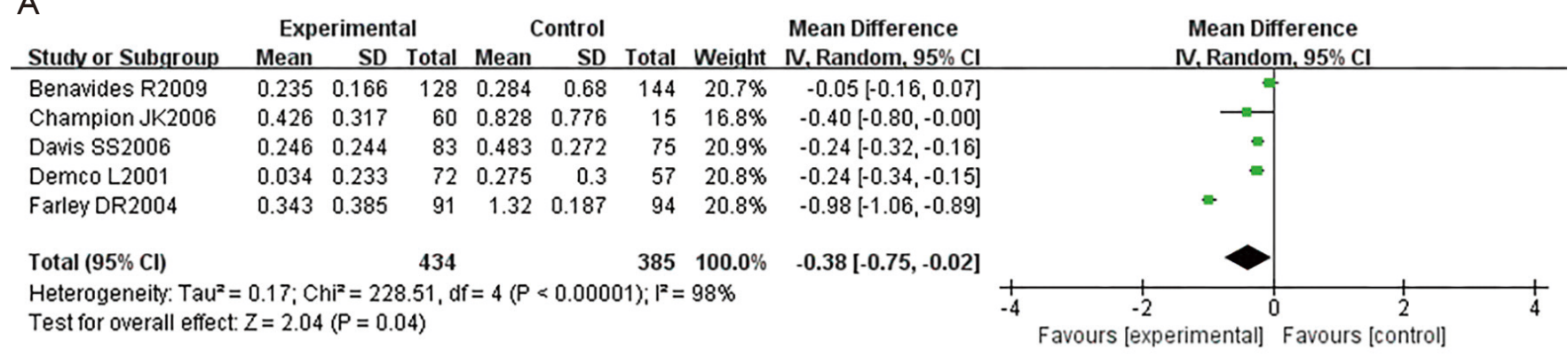

B

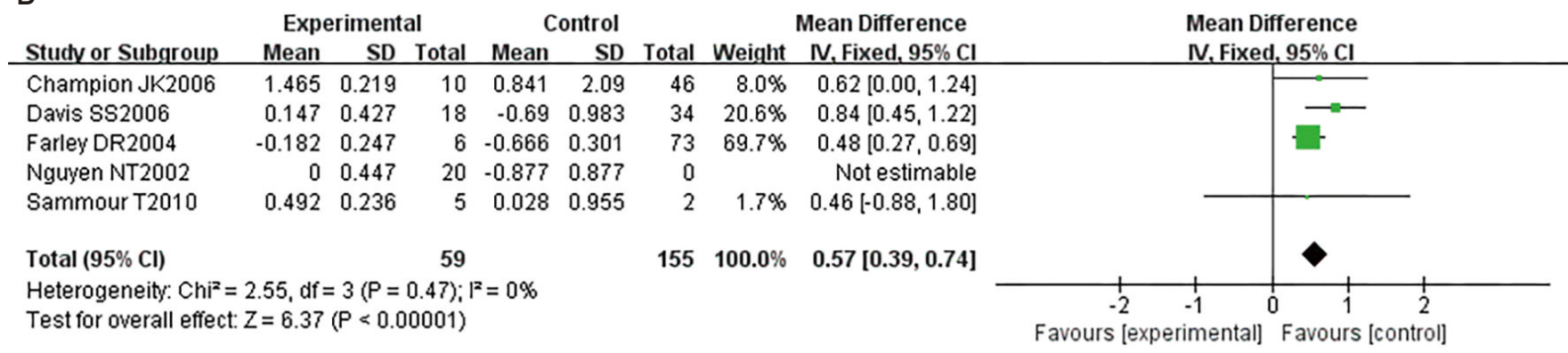

C

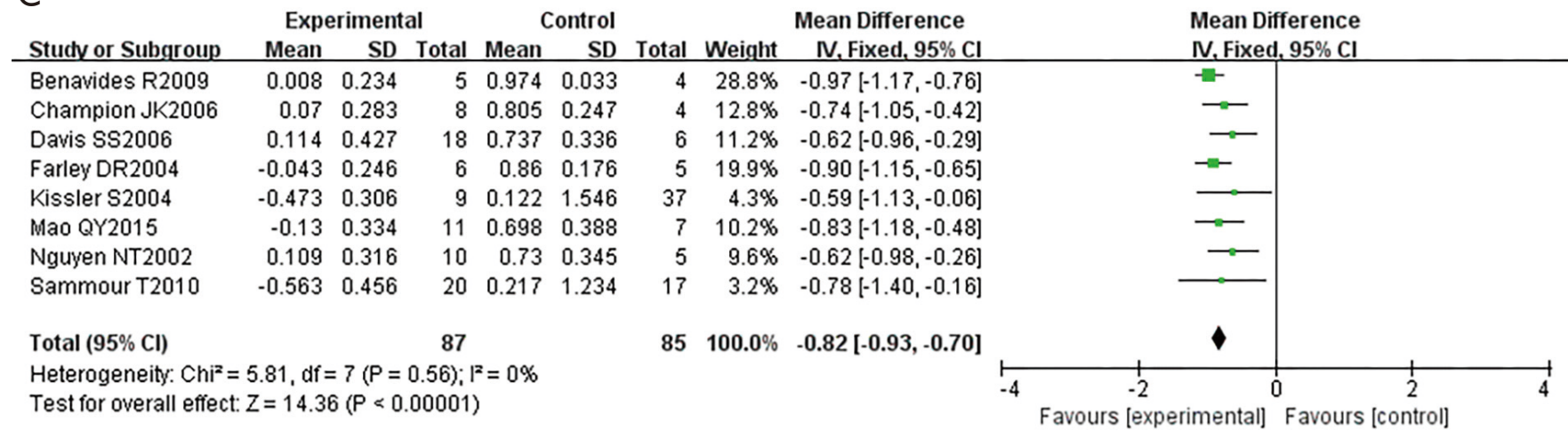

Figure 9 Forest plots of operation time, endoscope lens fogging, and gas consumption volume of heated humidified gas for gynaecological laparoscopy compared with standard room temperature dry gas (A, operation time; B, endoscope lens fogging; C, gas consumption volume).

carbon dioxide on the intraoperative and postoperative characteristics of patients receiving obstetrics and gynaecological laparoscopic surgery.

The results showed that the use of carbon dioxide humidification to about $90 \%$ to establish a pneumoperitoneum maintained the core temperature of perioperative patients, prevented laparoscopic endoscopic lens fogging, reduced peritoneal tissue damage and postoperative complications, decreased patient's perioperative pain and shortened their recovery time.

\section{Acknowledgments}

Funding: This study was supported by the Department of Science and Technology of Hebei Province (182777218).

\section{Footnote}

Reporting Checklist: The authors have completed the PRISMA reporting checklist. Available at https://dx.doi. org/10.21037/apm-21-1517 
Conflicts of Interest: All authors have completed the ICMJE uniform disclosure form (available at https://dx.doi. org/10.21037/apm-21-1517). The authors have no conflicts of interest to declare.

Ethical Statement: The authors are accountable for all aspects of the work in ensuring that questions related to the accuracy or integrity of any part of the work are appropriately investigated and resolved.

Open Access Statement: This is an Open Access article distributed in accordance with the Creative Commons Attribution-NonCommercial-NoDerivs 4.0 International License (CC BY-NC-ND 4.0), which permits the noncommercial replication and distribution of the article with the strict proviso that no changes or edits are made and the original work is properly cited (including links to both the formal publication through the relevant DOI and the license). See: https://creativecommons.org/licenses/by-nc-nd/4.0/.

\section{References}

1. Binda MM. Humidification during laparoscopic surgery: overview of the clinical benefits of using humidified gas during laparoscopic surgery. Arch Gynecol Obstet 2015;292:955-71.

2. Koninckx PR, Vandermeersch E. The persufflator: an insufflation device for laparoscopy and especially for CO2laser-endoscopic surgery. Hum Reprod 1991;6:1288-90.

3. Korell M, Schmaus F, Strowitzki T, et al. Pain intensity following laparoscopy. Surg Laparosc Endosc 1996;6:375-9.

4. Ott DE, Reich H, Love B, et al. Reduction of laparoscopic-induced hypothermia, postoperative pain and recovery room length of stay by pre-conditioning gas with the Insuflow device: a prospective randomized controlled multi-center study. JSLS. 1998;2:321-9.

5. Groene P, Gündogar U, Hofmann-Kiefer K, et al. Influence of insufflated carbon dioxide on abdominal temperature compared to oesophageal temperature during laparoscopic surgery. Surg Endosc 2020. [Epub ahead of print]. doi: 10.1007/s00464-020-08196-x.

6. Mao QY, Chen YC. Effect of warming carbon dioxide gas on postoperative pain in gynecologic laparoscopic patients. Psychologist 2015;21:70-1.

7. Sammour T, Kahokehr A, Hayes J, et al. Warming and humidification of insufflation carbon dioxide in laparoscopic colonic surgery: a double-blinded randomized controlled trial. Ann Surg 2010;251:1024-33.

8. Benavides R, Wong A, Nguyen H. Improved outcomes for lap-banding using the Insuflow device compared with heated-only gas. JSLS 2009;13:302-5.

9. Manwaring JM, Readman E, Maher PJ. The effect of heated humidified carbon dioxide on postoperative pain, core temperature, and recovery times in patients having laparoscopic surgery: a randomized controlled trial. J Minim Invasive Gynecol 2008;15:161-5.

10. Davis SS, Mikami DJ, Newlin M, et al. Heating and humidifying of carbon dioxide during pneumoperitoneum is not indicated: a prospective randomized trial. Surg Endosc 2006;20:153-8.

11. Champion JK, Williams M. Prospective randomized trial of heated humidified versus cold dry carbon dioxide insufflation during laparoscopic gastric bypass. Surg Obes Relat Dis 2006;2:445-9; discussion 449-50.

12. Diamond MP, Ott DE. Comment on: effect of heated and humidified $\mathrm{CO} 2$ during gynecologic laparoscopic surgery on analgesic requirements and postoperative pain. J Minim Invasive Gynecol 2005;12:462; author reply 462-3.

13. Yu TC, Hamill JK, Liley A, et al. Warm, humidified carbon dioxide gas insufflation for laparoscopic appendicectomy in children: a double-blinded randomized controlled trial. Ann Surg 2013;257:44-53.

14. Kissler S, Haas M, Strohmeier R, et al. Effect of humidified and heated $\mathrm{CO} 2$ during gynecologic laparoscopic surgery on analgesic requirements and postoperative pain. J Am Assoc Gynecol Laparosc 2004;11:473-7.

15. Farley DR, Greenlee SM, Larson DR, et al. Double-blind, prospective, randomized study of warmed, humidified carbon dioxide insufflation vs standard carbon dioxide for patients undergoing laparoscopic cholecystectomy. Arch Surg 2004;139:739-43; discussion 743-4.

16. Nguyen NT, Furdui G, Fleming NW, et al. Effect of heated and humidified carbon dioxide gas on core temperature and postoperative pain: a randomized trial. Surg Endosc 2002;16:1050-4.

17. Demco L. Effect of heating and humidifying gas on patients undergoing awake laparoscopy. J Am Assoc Gynecol Laparosc 2001;8:247-51.

18. Birch DW, Manouchehri N, Shi X, et al. Heated CO(2) with or without humidification for minimally invasive abdominal surgery. Cochrane Database Syst Rev 2011;(1):CD007821. Update in: Cochrane Database Syst Rev 2016;10:CD007821.

19. Sajid MS, Mallick AS, Rimpel J, et al. Effect of heated and humidified carbon dioxide on patients after laparoscopic 
procedures: a meta-analysis. Surg Laparosc Endosc Percutan Tech 2008;18:539-46.

20. Kumar S, Wong PF, Melling AC, et al. Effects of perioperative hypothermia and warming in surgical practice. Int Wound J 2005;2:193-204.

21. Binda MM, Molinas CR, Hansen P, et al. Effect of desiccation and temperature during laparoscopy on adhesion formation in mice. Fertil Steril 2006;86:166-75.

22. Erikoglu M, Yol S, Avunduk MC, et al. Electronmicroscopic alterations of the peritoneum after both cold and heated carbon dioxide pneumoperitoneum. J Surg Res 2005;125:73-7.

(English Language Editor: B. Draper)
Cite this article as: $\mathrm{Xu} \mathrm{P,} \mathrm{Li} \mathrm{Y,} \mathrm{Ren} \mathrm{J.} \mathrm{Meta-analysis} \mathrm{and}$ systematic review of influence of different humidified carbon dioxide on intraoperative and postoperative gynaecological laparoscopic surgery. Ann Palliat Med 2021;10(7):7992-8002. doi: 10.21037/apm-21-1517 